\title{
Model of formation of the value attitude of high school students to the Russian language in the lyceum educational environment
}

\author{
E.K. Al-Yanai* \\ Blagoveschensk State Pedagogical University, Blagoveschensk, Russia
}

\begin{abstract}
At the present stage of the development of pedagogy, due to the tendency to axiologize education, special attention should be paid to the spiritual and moral development and education of the child's personality. In the process of studying at school, the subject of «Russian language» occupies a leading position, the metasubject educational functions of which make it possible to involve schoolchildren in the spiritual richness of Russian culture and literature, and the cultural and historical experience of mankind. In this regard, it is necessary to provide scientific and methodological support for the process of forming a value attitude of students to the Russian language, which allows organizing Training and Learning activities of high school students on a value basis. The purpose of this publication is to theoretically substantiate the conceptual model of forming the value attitude of high school students to the Russian language in the lyceum educational environment. Research methods and methodology. In the course of the work, the following methodological approaches were used: axiological, system-activity, environmental approaches, modeling method. Research results.1. The conceptual model of the formation of the value attitude of high school students to the Russian language in the conditions of the lyceum educational environment has been substantiated. 2. The substantive and procedural aspects of the process of forming the value attitude of high school students to the Russian language are characterized. Practical significance. The model of the formation of the value attitude of senior pupils to the Russian language in the process of classroom and extracurricular educational activities in the conditions of the lyceum educational environment, aimed at understanding the Russian language as a national and cultural value, may be in demand in further studies considering the value approach in education, the value-oriented aspect of teaching native language, as well as to be used in the development of special courses for students, graduate students and teachers on the problems of learning a language from an axiological standpoint.
\end{abstract}

\footnotetext{
*Corresponding author: illina.a85@gmail.com
} 


\section{Introduction}

In recent decades, the global trend of axiologization of education has been enshrined at the state level, which is confirmed by pieces of legislative: "On education in the Russian Federation" [1], "Strategy of state cultural policy for the period up to 2030" [2], Decree of the President of the Russian Federation of 12.24.2014 No. 808 "On the approval of the State cultural policy Framework" [3], "The concept of spiritual and moral development and education of the individual" [4], etc., where the demand for valuebased learning and education of the student's personality is noted.

The legislation declares a special status of the subject "Russian language", the metasubject functions of which influence the formation of the child's personality in the process of his schooling. The native Russian language is a means of familiarizing with the spiritual wealth of Russian culture and literature, the main channel for the socialization of the individual, familiarizing it with the cultural and historical experience of mankind. However, the language, being the custodian of culture, in turn, becomes a national and cultural value, the student needs to adopt value orientations as the most important elements of the axiosphere of the linguistic personality, and special attention should be paid to the formation of the value attitude of students to the Russian language.

Thus, a contradiction has been revealed between the presence of a certain practice of forming the value attitude of high school students to the Russian language and the absence of a holistic theoretically grounded system that allows organizing the Training and Learning activity of high school students on a value basis.

The purpose of this publication is to theoretically substantiate the conceptual model of forming the value attitude of high school students to the Russian language in the lyceum educational environment.

Research methods. In the course of the work, the following methods were used: the study of scientific and methodological literature on the topic of research, generalization, modeling.

\section{Literature review}

The study of the problem of forming a value attitude is a topical issue today. This is the subject of modern psychological, pedagogical, linguo-methodological research, which assert the need for axiologically oriented education and upbringing of schoolchildren. Let us list the most promising areas of research and the most significant publications of foreign scientists in recent years (2017-2020). A considerable amount of research is focused on identifying the factors of the formation of value attitudes towards language learning $[5,6$, $7,8,9,10]$, the study on the impact of the value attitudes of schoolchildren and students on the subject on the quality of learning the material $[11,12,13,14]$.

There is an increased interest of researchers in the study of factors and conditions conducive to the formation of a value attitude to language. Research conducted by Lasagabaster D., S. Al Darwish, A. Arwin et al. reaffirm the importance of motivation as a key factor. $[9,6,8]$. The work of A. Arwin, who notes the need for integrative (intrinsic) motivation for language learning [8], is particularly noteworthy. J. C. Santana, A. GarcíaSantillán, C. Ferrer-Nieto, M. J. López-Martínez rightly point out intrinsic motivation to learn a language contributes not only to the successful mastery of both native and foreign languages, but also to the formation of a value attitude towards it [12].

R. Bargard, Z. Sharafoddin, M. Afzalaghaee (Iran) specify that academic performance is one of the most significant factors contributing to sustainable motivation to learn a language [7]. While an inverse relationship has also been proven, which consists in the influence of attitudes towards the target language on academic performance [13]. 
Also, a number of publications are devoted to the problem of modeling education and upbringing on a value basis. For example, researchers K. Komalasari, D. Saripudin, developed and tested a model of civic education of schoolchildren based on life values. A life values training program involves a variety of activities, such as the development of social cohesion skills. [15]. Thus, the relevance of the axiologization of the process of education and upbringing has been confirmed.

Analysis of foreign sources has shown that the problem of forming a value attitude to language is under examination by researchers from different countries. It is worth noting the most significant findings of foreign researchers: the main factor influencing the formation of a value attitude towards the target language is motivation; intrinsic motivation, which directly reflects the value attitudes and priorities of students, contributes not only to the successful mastering of the language, but also to the formation of a value attitude towards it.

In our view, despite the large amounts of work devoted to the problem of the formation of the value attitude of schoolchildren and students in general, there is clearly not enough work in the field of the formation of the value attitude of schoolchildren to their native language. First of all, it is necessary to develop scientific and methodological support for the process of forming the value attitude of students to the Russian language, which makes it possible to organize the Training and Learning activity of high school students on a value basis. In the process of studying at school, the subject of «Russian language» occupies a leading position, the metapedmetic educational functions of which make it possible to involve schoolchildren in the spiritual richness of Russian culture and literature, and the cultural and historical experience of mankind. Literature review confirms the relevance of the research problem.

\section{Research methods and methodology}

Modeling is one of the most effective methods of scientific knowledge in modern pedagogy. In the view of Yu. Z. Kushner, the model is a hypothesis expressed in a visual form [16, p. 51]. The construction of a model involves the creation of a sample, a certain ideal of the educational process, including the structure (target, content, organizationalactivity, analytic-productive components), content and mechanisms of influence on the personality. Conceptual modeling of the pedagogical process includes goals, objectives, approaches to learning, pedagogical conditions for the implementation of the model, as well as the principles of learning. Let us present a conceptual model of the formation of the value attitude of high school students to the Russian language in the context of a lyceum educational environment.

We proceeded from the following conceptual provisions when designing the model.

The category "value attitude to the Russian language" is understood by us as the value-semantic space of the spiritual activity of the individual, characterized by the manifestation of interest in linguistic phenomena reflecting the history, culture of the native language, regional traditions, the meaningful use of the wealth of the native language as the only source of expression of thoughts and feelings, the manifestation care for the purity of the language and its preservation as a national treasure, accompanied by the internalization of the fundamental spiritual values accumulated in the language.

The formation of a value attitude towards the Russian language is a pedagogical process aimed at assimilating universal and national spiritual values, one of which is the native language, culture and traditions of its people; contributing to the development of a sense of responsibility for the careful use of the Russian language, awareness of its cultural significance. 
The system of forming the value attitude of high school students to the Russian language is aimed at understanding the Russian language as a national and cultural value and enriching the concept sphere of students, expanding their cultural horizons, and developing the worldview of a highly moral personality.

The conceptual model is based on the axiological, system-activity, environmental approaches.

Axiological approach (L.V. Blinov [17], M.V. Boguslavsky [18], Zagvyazinsky V.I. [19], Z.I. Ravkin [20], V.A. Slastenin, Chizhakova G.I. [21] and others) allows one to present the value organization of educational and cognitive activity in the process of teaching the Russian language.

The axiological approach contributes to the formation of the moral, ideological and civic position of students. The federal State educational standard of basic general and secondary general education at the goal level consolidates the axiological approach to the formation of the content of education, which is reflected in the orientation of the Standard to the formation of the personal characteristics of the graduate (profile of basic school graduate: loves his land and his homeland, knows Russian and his native language, respects his people, his culture and his spiritual traditions; who understands and accepts the values of human life, the family, civil society, the multinational Russian people, humanity, etc.) [22]. From the point of view of the axiological approach, of particular interest to us is also the organization of the pedagogical process, which would ensure the formation of the value orientations of the individual, namely the formation of the value attitude towards the Russian language.

System-activity approach (V.P. Bespalko [23], V.S. Gershunsky [24], A.G. Kuznetsova [25], A.V. Khutorskoy [26], E.G. Yudin [27] and others) provides the opportunity to consider the process of forming the value attitude of high school students to the Russian language as a single system, the components of which function in accordance with the goal and planned results of lesson and extracurricular activities. The system-activity approach helps to reveal the activity aspect of the content component of the model we are designing. A special feature of the developed system is its focus on the personal development of the student on the basis of the formation of personal universal educational actions (according to the Federal State Educational Standard) that ensure the self-determination of a person, the choice of value, moral and aesthetic guidelines, motivation for learning in general and for learning the Russian language in particular. A.V. Khutorskoy calls personal Universal Learning Activities a value-semantic (ideological) activity, which he gives the following definition: "Value-semantic (ideological) activity determines and develops the emotional values of the student, his ability to self-knowledge and self-movement, the ability to determine his place and role in the world, family, team, nature, in the state, national and universal aspirations, patriotic and tolerant personality traits, etc. " [26, p. 224]. The result of the developed model is a system for the formation of the value attitude of high school students to the Russian language, which includes value-worldview, cognitive-reflexive and activity-behavioral criteria and indicators for determining the level of formation of the value attitude of high school students to the Russian language as personal results of education.

Environmental approach (OS Gazman [28], Yu.S. Manuilov [29], V.A. Petrovsky [30], V. I. Slobodchikov [31], V.A. Yasvin [32]), confirms the importance of the educational environment in the formation of value orientations of the student's personality.

The implementation of the highlighted theoretical and methodological approaches is carried out within the framework of both lesson activities (in the study of the subject area "Russian language") and extracurricular activities. 


\section{Research results}

The practical demonstration of the conceptual model is the system of forming the value attitude of students to the Russian native language and the cultural heritage of the native land on the basis of axiologically oriented teaching material, including literary and local history material. The model is a logically built system of content, forms, methods, teaching aids aimed at achieving the goal. The structure of the conceptual model includes 4 blocks: target, substantive, procedural and effective.

\subsection{Target block}

This block is formed under the influence of the social-sector procurement (the personality of a high school student who treats the native language as a national value) and the Federal State Educational Standard of basic general and secondary general education.

The goal of axiologically oriented teaching: the formation of a value attitude towards the native language of high school students in the conditions of the lyceum educational environment. The formation of a value attitude to the Russian language presupposes a pedagogical process aimed at qualitative changes in the student's personality associated with the interiorization of universal and national spiritual values, one of which is the native language, which contributes to the development of a sense of responsibility for the careful use of the Russian language, awareness of its cultural significance. One of the most important means of developing the spiritual and moral world of the student, his valueorientational culture, and national consciousness is the national-cultural component in teaching the Russian language.

Work in the axiological aspect is thus integrated into the traditional study of the school course of the Russian language. The value-based approach must be organically introduced into the main course of the Russian language, and not taken out to extracurriculal classes. Each lesson of the Russian language should be permeated with the idea of axiologization, focused on the development of attitudes towards the native language as a national and cultural value.

\subsection{Content block}

This block reflects the components of the process of forming a value attitude towards their native language in high school students in the conditions of the lyceum educational environment: informational, activity-oriented, socio-cultural.

The information component: mastering the body of knowledge in the discipline "Russian language". A holistic pedagogical process in the unity and interdependence of the individual and collective organization of educational and cognitive activities contributes not only to improving the quality of education, but also to the formation of a system of value orientations among students, which determine their attitude to their native language as a national and cultural value. In the process of educational activities, due to the use of the value content of the school course of the Russian language and the enrichment of the content of both lesson and extracurricular activities (elective courses, design and research activities) with axiologically oriented teaching local history material, students become aware of spiritual and moral categories, the formation of a value attitude towards Russian language and the formation of the moral position of students. As a result, favorable conditions are provided for the upbringing of spiritual and moral values of the national culture among high school students in the conditions of the lyceum educational environment. 
The main areas of work with axiologically oriented teaching material: analysis of vocabulary with a national-cultural component (cultural concept), analysis of a cultural text rich in precedent phenomena. Cultural texts (based on the works of Amur authors), storing knowledge about the world, reflect the spiritual life of the nation, its culture, and therefore form the value picture of the world of students. It should be noted that each direction is a system of exercises focused on a comprehensive study of the linguistic unit under consideration and the value comprehension of the elements of the national concept sphere by students.

The activity component is the technology of value-oriented education in accordance with the systematization of G.K. Selevko (technology of self-developing education), which presupposes a system of methods, forms of organizing educational activities aimed at forming the value attitude of high school students to the Russian language.

Forms, methods, content of lesson and extracurricular educational activities:

- attracting the attention of high school students to the value aspect of the phenomena studied in the lessons of the Russian language;

- the use of interactive forms of student work in the lesson, including those used in higher education: discussions, seminars, group work or work in pairs, intellectual games, tournaments;

- design and research activities;

- participation in conferences;

- expeditions for students to the historical places of their native city and region in order to study linguistic phenomena;

- literary expeditions;

- elective course "Journalism": literary and journalistic project (lyceum newspaper);

- elective course "Cultural values of the Amur Cossacks";

- problem-value communication in classroom and extracurricular activities, aimed at fostering a culture of communication, respect for other people's opinions and the ability to defend their own, tolerant of the diversity of people's views.

The sociocultural component presupposes the organization of interaction between a teacher and a student, organized in such a way that conditions are created for the processes of interiorization and exteriorization in order to form a system of values in students, including a value attitude to educational activities in general, to the native language as a national cultural value, as well as value self-determination of older adolescents. The teacher creates the emotional background of the lesson, together with the students plans their educational and cognitive activities, reveals the value potential of the teaching material. The lyceum educational environment of a pedagogical university is a special educational environment that is included in the socio-cultural environment of the university. As a rule, the intellectual background of the lyceum class differs from the general education class, since it involves the actualization of the corresponding motivation of students.

The system of value-oriented teaching of the Russian language, including methods, techniques, means and forms of organizing training, will be presented in detail below when characterizing the procedural block of the model.

\subsection{Procedural block}

This block is presented by the organizational and pedagogical conditions for the formation of the value attitude of high school students to the Russian language and the stages of the implementation of this process. Organizational and pedagogical conditions ensure the implementation of the content block, are interconnected by each of its components.

The learning process is a purposeful, socially conditioned and pedagogically organized process of development ("creation") of the personality of trainees, taking place on the basis 
of mastering systematized scientific knowledge and methods of activity, reflecting the composition of the spiritual and material culture of mankind [33, p. 186]. The pedagogical process is determined by the goal, which reflects the result of pedagogical interaction, the selection of the appropriate content and is implemented by methods, means, teaching methods and forms of the training organization.

Thus, the procedural block is a description of the system for the formation of a value attitude towards the native language (value picture of the world) of high school students, involves a step-by-step description of the process of lesson and extracurricular activities, a set of content, methods, forms of organization of training, means, techniques for achieving the planned results.

Let us characterize each stage of the formation of the value attitude of high school students to the Russian language.

1. The organizational-target (motivational-value) stage is aimed at the formation of sustainable motivation for learning the language, at identifying the main criteria and indicators of the effectiveness of the formation of the value attitude of high school students to the Russian language in the context of the lyceum educational environment, as well as at predicting the expected results.

Based on the analysis of the value priorities of students, the value picture of high school students is reconstructed, the presence and place of the value "Russian language" / native language "in the axiosphere of students is determined.

2. The content-activity stage is aimed at planning and implementing the process of forming the attitude of high school students to the Russian language as a national-cultural value in classroom and extracurricular activities.

Value-oriented teaching of the Russian language should be carried out with the help of teaching material with axiological potential: vocabulary with a national-cultural component of meaning, cultural concepts, Russian folk proverbs, sayings and precedent texts, cultural texts. Working with this teaching material deepens students' understanding of the peculiarities of the mentality of the people and is a powerful means of introducing the younger generation to the national and cultural picture of the world. The system of forming the value attitude of schoolchildren to the Russian language includes extracurricular activities as an addition to the main content of the course "Russian language". These are elective courses "Journalism" and "Cultural values of the Amur Cossacks".

In accordance with the requirements of the Federal State Educational Standard, in the framework of extracurricular activities, it is planned to organize educational, research and project activities of students, which is an integral part of the educational process. The results and products of design and research work should be presented at scientific and practical conferences. The implementation of educational research, participation in olympiads, competitions, intellectual marathons, subject weeks, thematic events of city and regional significance contributes not only to the self-realization of schoolchildren, but also to the enrichment of their axiosphere.

3. The reflexive-evaluative stage presupposes the interiorization of the value attitude of high school students to the Russian language. At this stage, students are repeatedly offered a set of methods, as well as a diagnostic test, the results of which make it possible to assess the value priorities of students and the level of formation of the value attitude of high school students to the Russian language.

\subsection{Effective block}

This block is represented by a complex (system) of criteria and indicators of the level of formation of high school students' value attitude to the Russian language. 
The expected result of the activity in the process of implementing the system of valuebased learning is presented in the effective component. The result of the work, reflecting the real level of the value attitude of high school students to the Russian language, is the personal learning outcomes - the levels of formation of value-worldview, cognitivereflexive and activity-behavioral criteria.

At the moment, teaching lacks a clear description of the components, criteria and indicators by which the level of formation of the value attitude of high school students to the Russian language should be assessed, as well as diagnostic tools. As part of the study, we have identified value-worldview, cognitive-reflexive, activity-behavioral criteria, formulated level indicators for each criterion.

The value and worldview criterion assumes that the student understands and accepts the Russian language as one of the main national and cultural values of the Russian people, realizes the aesthetic value of the Russian language, demonstrates respect for the native language, pride in it, the need to preserve the purity of the Russian language as a phenomenon of national culture, appreciates involvement in the Russian language and Russian culture. The student shows interest in the study of the culture of the people, reflected in the language, and linguistic means with a national-cultural component of meaning, is included in the conversation, showing an active interest in the material reflecting the features of Russian national culture, asks additional questions.

The cognitive-reflexive criterion provides that the student is aware of the Russian language as the highest socially significant, spiritual and historical value, is convinced of the need to preserve and protect the Russian language, and is aware of the responsibility in relation to the native language and speech. Strives to replenish knowledge of the Russian language, is capable of self-evaluation based on observation of his speech. Has an idea about the culture and traditions of the Russian people, about the language as a source of cultural information, about dictionaries as sources of linguocultural information, knows how to work with a dictionary. The student demonstrates knowledge and understanding of cultural concepts, linguistic units with national and cultural specifics, texts with a national and cultural component.

The activity-behavioral criterion assesses how much the student is aware of his personal responsibility for the preservation of the Russian language as a cultural heritage, strives for speech self-improvement. In a situation of moral choice, he demonstrates the formed value attitudes of the individual that correspond to the norms of morality and ethics. Knows how to find information about the cultural component of the meaning of linguistic units, correctly understands and explains the meaning of linguistic units, taking into account their cultural component. Can recall and name proverbs on certain topics. Correlates the meaning of a phrase with proverbs and selects a phrase for a proverb that expresses the same thought.

We assess the value attitudes of high school students towards the Russian language from the standpoint of the personal results of mastering the Russian language programs by primary and secondary school students, regulated by the Federal State Educational Standard.

\section{Conclusion}

The conceptual model of the formation of the value attitude of high school students to the Russian language in the conditions of the lyceum educational environment is represented by 4 blocks: a target block, a content block, a procedural block, an effective block. The purpose of the model implementation: the formation of the value attitude of high school students to the Russian language in the conditions of the lyceum educational environment. The content block is presented by pedagogical conditions, including an information 
component (enrichment of the content of education with axiologically oriented teaching local history material); the activity component, represented by the technology of valueoriented education, forms and methods; a socio-cultural component, implying a valueoriented process of pedagogical interaction.

The system of forming the value attitude of high school students to the Russian language includes methods, techniques, means, forms of organization of education, consists of 3 stages. Within the framework of this system of work at the organizational-target stage, on the basis of diagnostics, the value priorities of high school students are identified, the value picture of the world is projected and the place in it of the basic value "Russian language" is revealed, the level of formation of the value-worldview, cognitive-reflective and activity-behavioral criteria is determined. At the content-activity stage, within the framework of the lesson and extracurricular activities, value-oriented teaching of the Russian language is carried out, at the reflexive-evaluative stage, the achieved level of formation of value-worldview, cognitive-reflective and activity-behavioral criteria is assessed, on the basis of which a conclusion is made about the degree of interiorization of the value relationship to the Russian language.

The proposed model of the formation of the value attitude of high school students to the Russian language in the process of classroom and extracurricular educational activities in the conditions of the lyceum educational environment, aimed at understanding the Russian language as a national cultural value, can be used as a methodological basis for organizing the educational process, and can also be it is in demand in further studies that consider the value approach in education, the value-oriented aspect of teaching the native language, to be used in the development of special courses for students, graduate students and teachers on the problems of learning a language from an axiological standpoint.

\section{Acknowledgement}

The author expresses gratitude to Karnaukh Nadezhda Valentinovna, Doctor of Pedagogical Sciences, Professor of the Federal State Budgetary Educational Institution of Higher Education, scientific supervisor of the work. The research was carried out on the basis of the Federal State Budgetary Educational Institution of Higher Education "Blagoveshchensk State Pedagogical University". The author thanks the anonymous reviewers of the article, whose comments have significantly improved its quality.

\section{References}

1. On education in the Russian Federation, Federal Law No. 273-FZ dated December 29 (2012) http://base.garant.ru/

2. Strategy of the state cultural policy for the period up to 2030, Order of the Government of the Russian Federation No. 326-r dated February 29 (2016) https://www.garant.ru/

3. On the approval of the Fundamentals of State Cultural Policy, Decree of the President of the Russian Federation of 24.12.2014 No. 808, http://kremlin.ru/

4. A. Ya. Danilyuk, A.M. Kondakov, V.A. Tishkov, The concept of spiritual and moral development and education of the personality of a citizen of Russia, 24 (2009)

5. B. M. Sakul, ELT in Asia in the Digital Era: Global Citizenship and Identity, 398

6. Al. S. Darwish, International Journal of English Language Teaching, 5(6), 1 (2017)

7. R. Bargard, Z. Bargard, M. Afzalaghaee, Future of Medical Education Journal, 10(3), 13 (2020)

8. A. Arwin, Journal Akrab Juara, 4(2), 66 (2019) 
9. D. Lasagabaster, The Modern Language Journal, 101(3), 583 (2017)

10. X. San Isidro, D. Lasagabaster, The Language Learning Journal, 1 (2020)

11. A. Habók, A. Magyar, Frontiers in psychology, 8, 2358 (2018)

12. Santana J. C., A. García-Santillán, C. Ferrer-Nieto, M.J. López-Martínez, Journal of Psychological and Educational Research, 2, 165 (2017)

13. N. Sölpük, The Effect of Attitude on Student Achievement, In The Factors Effecting Student Achievement, 57 (2017)

14. H. Kocadayığulları, The differences between Turkish and Polish students' attitude and motivation towards English as a foreign language (Master's thesis, Çă̆ Üniversitesi Sosyal Bilimler Enstitüsü) (2017)

15. K. Komalasari, D. Saripudin, International Journal of Instruction, 11(1), 395 (2018)

16. Yu. Z. Kushner, Methodology and methods of pedagogical research, 66 (2001)

17. L.V. Blinov, Axiology of postgraduate education of teachers, 2, 142 (2003)

18. M.V. Boguslavsky, Modernization of Russian education: problems and solutions, 96 (2004)

19. V.I. Boguslavsky, General pedagogy, 391 (2008)

20. Z.I. Ravkin, Reader on pedagogical axiology, 480 (2005)

21. V.A. Slastenin, G.I. Chizhakova, Introduction to pedagogical axiology, 192 (2003)

22. Federal state educational standard of secondary (complete) general education, By order of the Ministry of Education and Science of the Russian Federation No. 413 of May 17 (2012) http://www.obrasovanie.edusite.ru/

23. V.P. Bespalko, Pedagogy, 7, 7 (1990)

24. V.S. Gershunsky, Problems of increasing the effectiveness of the pedagogical process on the basis of optimization ideas, 160 (1985)

25. A.G. Kuznetsova, Development of the methodology of the systems approach in domestic pedagogy, 152 (2001)

26. A.V. Khutorskoy, Pedagogy: Textbook for universities, Third generation standard, 608 (2019)

27. E.G. Yudin, Systematic approach and principle of activity, 70 (1978)

28. O.S. Gazman, Director of the school, 3, 10 (2017)

29. Yu. S. Manuilov, Environment approach in education, 2, 157 (2002)

30. A. V. Petrovsky, Personality. Activity. Collective, 256 (1982)

31. V. I. Slobodchikov, New values of education: cultural models of schools, 7, 177 (1997)

32. V. A. Yasvin, Educational environment: from modeling to design, 365 (2001)

33. L. D. Stolyarenko, Pedagogy, Series "Textbooks, tutorials", 448 (2000)

34. M. Rokeach, The Nature of human values, 438 (1973) 